\title{
The Cultural Remodeling of Public Art in the Consumption Era
}

\author{
Qiangqiang Luo $^{1, *}$ \\ ${ }^{1}$ Xiamen Academy of Arts and Design, Fuzhou University, Xiamen, Fujian 361000, China \\ *Corresponding author. Email:1358783673@qq.com
}

\begin{abstract}
The prosperity of mass culture in the consumption era makes public art present many different characteristics from the past. The secular characteristics of mass culture representations are first manifested in that it no longer only pays attention to issues such as the sublime, the sacred, and the classics that can't be touched and only be admired in a far view. The phenomenon of "dedifferentiation" in mass culture has blurred many boundaries of public art. As an open and emerging art, it encompasses many art categories, exists in various public spaces and places, and is integrated into social life with its interactive characteristics. It promotes cultural democracy in terms of interaction and visualization, and eliminates the inequality caused by people's knowledge level in cultural consumption. This paper analyzes the characteristics of public art in the consumption era, proposes the method of reshaping public art that adapts to the current situation, namely, the three directions of cultural breakthrough, multiple interaction and context retention, and takes the atrium landscape of the teaching building of Xiamen Academy of Arts and Design as an example to apply the research conclusions in practice.
\end{abstract}

\section{Keywords: consumption era, public art, cultural remodeling, cultural consumption, mass culture}

\section{INTRODUCTION}

In recent years, public art has developed rapidly. In addition to decorating and beautifying environmental spaces, it has also increasingly assumed the mission of promoting social values. In the process of communication and integration with world culture, public art design is gradually merging with the cultural characteristics of the consumption era. On the one hand, it has strengthened the interaction between public art and the public, and on the other hand, there have been some drawbacks of the consumption era. How should public art develop in the consumption era? How to make public art maintain its uniqueness in the consumption era? The study of public art in the art remodeling in the consumption era will enable public art to integrate with local culture, truly understand the needs of the public and generate emotional connections.

\section{THE CULTURAL ANALYSIS OF PUBLIC ART}

\section{A. Diversified development of public art}

1) The concept of public art: The term public art is composed of the terms "public" and "art". The word "public" means "commonality" and has the meaning of common people. The etymology of "citizen" is civis, and the abstract noun civitas representing citizenship is derived from it. After the continuous increase of abstract connotation, the term eventually becomes synonymous with commonality, which refers to a residential area of people slightly larger than the area in English [1]. The term "art" means "technology, ingenuity, and fine arts", which means that people form an intentional picture in their minds. "Art" is generally related to vision, and it is mainly to leave an impression in human vision through two-dimensional or threedimensional reproduction.

2) Development of public art: As an independent art form, public art, from the art of sculpture on the shelves that serves a few people to the public sculpture of public life, is produced with the development of society and the progress of civilization. As a discipline, it was first proposed in the American Roosevelt's Art Percentage Plan and was gradually mature and popular in Europe. And with the acceleration of urban construction, it became increasingly prosperous. However, due to the rapid development and following foreign art forms, there are still some problems behind the prosperity of Chinese public art development.

China's early public art combined with the use of political power in the superstructure, and was mostly manifested as monument art, mainly commemorating leaders and historical events. After the reform and 
opening up, public art works with urban sculptures and murals as the main manifestations once entered a period of rapid development. It developed rapidly in public places in coastal cities in China. Since the 1990s, with the rapid development of China's economy, the pace of urban construction has accelerated, and the supporting urban landscape construction and public works have become more abundant. The forms of public art have become more diversified, and new public art forms such as pop and installations have appeared, which decorate public occasions such as urban squares, greenbelts and commercial streets, making the public life more colorful and meeting people's increasing spiritual needs. Public art begins to not only be limited to simple urban sculpture creation, but to emphasize public participation, gradually highlighting the important "public" attribute. Sculpture parks focusing on urban sculptures have appeared in major cities in China, providing a broader space for public art and a space for people to communicate. The birth and popularization of sculpture parks marked the gradual maturity of Chinese urban sculptures ("Fig. 1" and "Fig. 2").

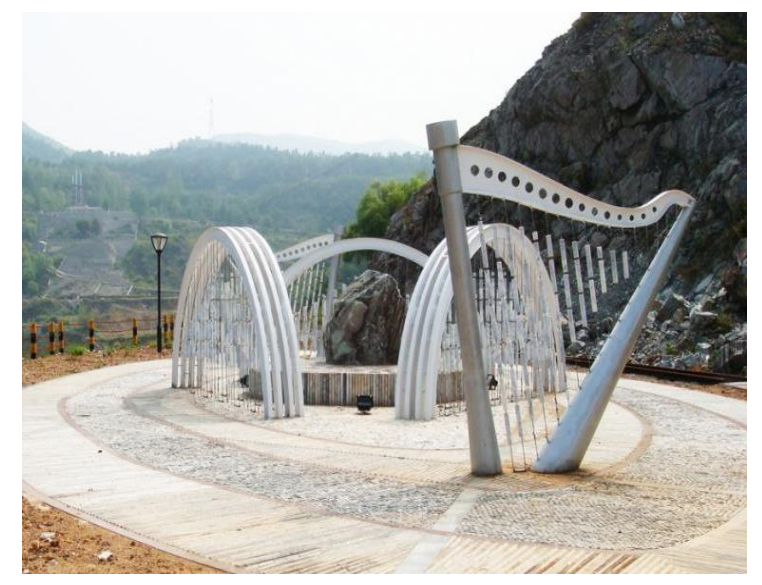

Fig. 1. Sculpture in Huangshi National Mine Park, Hubei.

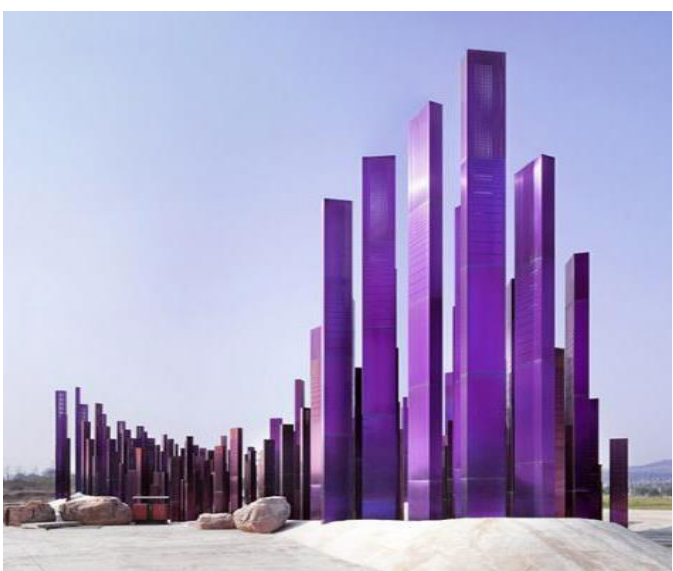

Fig. 2. Landscape sculpture in Xiangyang China Crape Myrtle Garden.

\section{B. The value of public art}

Art has the effect of influencing the soul. All forms of art are based on the transfer of feelings from human senses to the human brain to form abstract thinking, which then influences and changes people's behaviors and emotions. Public art embodies the function and meaning of its own existence in this way. First of all, as a category of art, public art can show its own aesthetic function through the decoration and beautification of environmental space to meet the needs of public visual enjoyment. When people's visual senses are satisfied, they will inevitably get a sense of pleasure, so that their emotions can be sublimated. This is a benign interactive relationship formed between public art and people. When people enter a new environment, the first thing that attracts people's visual attention is not the common buildings or decorations, but the public art with aesthetic orientation and aesthetic edification. This is because public art forms are easier to achieve emotional exchanges and communication with people. The reason why public art attracts the public's attention is that it possesses the necessary popularity for communicating with the public, which is determined by another psychological need of the public. Public art must appear in a way that the public love to see and hear, and whether it is content, subject matter or form, it should conform to the public's appreciation habits and aesthetic taste. This is the biggest difference between public art and easel art in creation. Public art should not only focus on the expression of personal emotions, but should focus on the aesthetic needs of the public. The subject and content expressed in public art are mostly familiar to the public, and most of them are realistic in modeling. Even if they are in abstract form, they are mostly expressed in an aesthetic way. In short, the expression form of public art should mainly meet the public's aesthetic standards. Only when public art enters the public's life can the aesthetic function of public art be truly brought into play. Throughout history, the existence value of any public art is manifested after satisfying the public's psychological needs. Of course, the public's aesthetic expectations and psychological needs for public art will inevitably become a potential driving force for the expansion and promotion of public art functions.

\section{Cultural connotation of public art}

Another key function of public art that serves the society and is beneficial to the harmonious development of society is that it highlights the distinctive cultural spiritual dimension and extols positive social values. The society has given public art such an outstanding and glorious mission, that is, to promote the national spirit and national culture through publicity, encourage the people to be aggressive, and maintain social morality and promote social harmony as their responsibility, which will become an inescapable 
social responsibility of public art. Therefore, when public art is presented to the public, it is not only restricted by space and environment, but also abides by its social responsibilities in terms of the subject and content and art form, which need to fully reflect the humanistic spirit of the times. Only in this way can China's public art play the role of uniting and educating the people, and become a carrier of social morality ("Fig. 3").

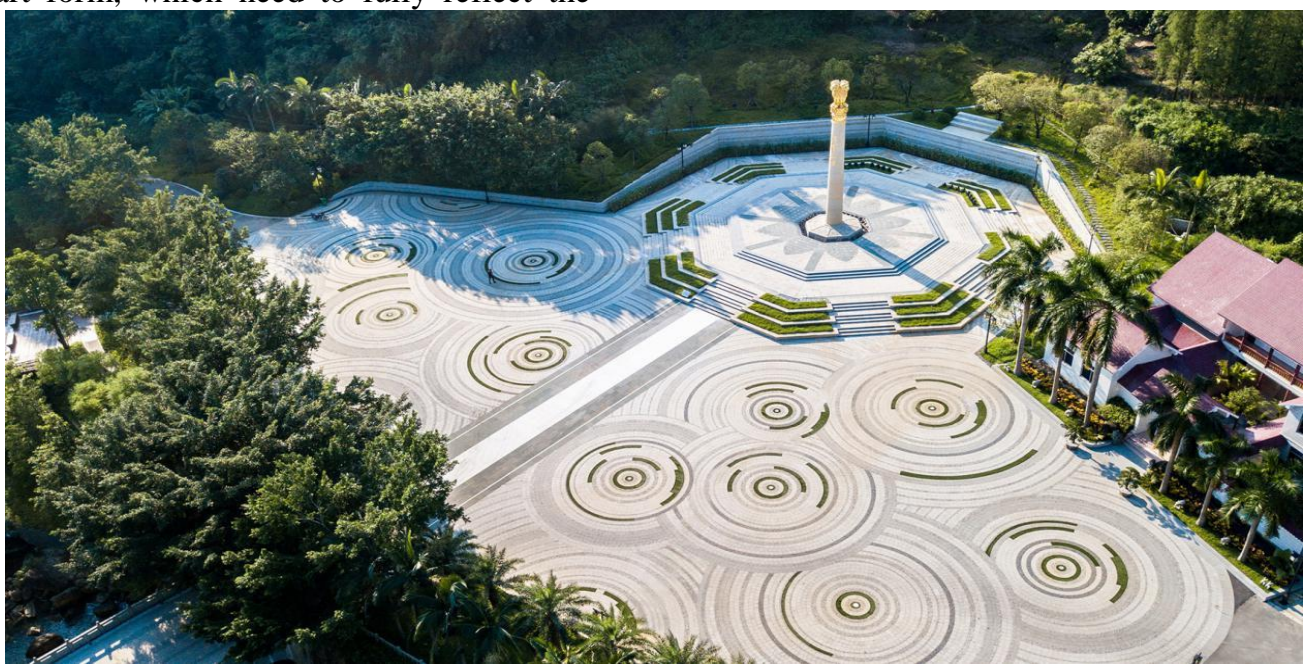

Fig. 3. Sculpture of Huizhou Luofu Pure Land Memorial Park.

With the development of social economy and the exchange and integration of the world's diverse cultures, the level of people's needs is gradually increasing and expanding. Public art gradually shows its role in satisfying the public's psychological and spiritual needs for the environment. The art of each era has its own unique cultural connotation and performance characteristics. The aesthetic effect of art is manifested in the way of social culture, guiding the public's aesthetic orientation, and the progress of social culture promotes the development of public art to a higher level. Public art, public psychology and social needs have thus formed a unity of mutual influence and mutual promotion. Only when public art is adapted to the pace of society and the times, can it truly reflect its public significance and promote social development.

\section{RESEARCH ON MASS CONSUMER PSYCHOLOGY IN THE CONSUMPTION ERA}

\section{A. The definition of consumerism}

Consumerism culture is a cultural trend of thought and way of life that appeared with the advent of Western consumer society in the 20th century, and a cultural phenomenon with the value of consumerism as the core. Consumerism originated in the United States in the 1920s and 1930s, and began to spread to Western Europe and Japan in the 1950s and 1960s. As a result, research on the cultural characteristics of consumerism has become increasingly popular. Nowadays, mass culture research pays more and more attention to the interpretation of consumer society and consumerist cultural symbols [2]. Mass culture relies on the rapid growth of the consumer culture era, and the birth and development of public art can't be separated from the infiltration of mass culture. Symbolic value, as the common ground of consumer culture and public art, is inseparable from the mass as a carrier.

\section{B. Modern consumer society and consumerism}

The main characteristic of a consumer society is that "the production capacity is surplus relative to the modest and thrifty traditional lifestyle. For the production and reproduction of the mode of production itself, the society must continuously stimulate consumption and make large-scale consumption the basic way of life of the society." According to Baudrillard's "Consumer Society", at this time, in the era of rapid economic development, all kinds of goods sold in stores have already been advertised and branded with an exquisite "coat". When customers unconsciously consume goods, they are also consuming the culture of goods, which are ultimately represented by symbols. China implemented a major reform of its economic system in the $1990 \mathrm{~s}$, and the market economic system has elevated people's lives to a new level. While the people continue to enrich their material level, their spiritual culture has also been gradually improved. Consumerism culture began to emerge under such a breeding ground. Through continuous improvement of production levels and communication methods, consumer groups of different levels and backgrounds have become the target of the market. Therefore, although China has not yet entered the consumer era, it is already an era in which consumerist culture dominates. 


\section{Consumption trends of mass culture and public art}

To a certain extent, mass culture encompasses the cultural orientation and ideological consciousness of the contemporary masses, and it has the characteristics of easy to be guided, wide range, and no individuality. Mass culture is different from elite culture. It is easy to understand, but it is often not free to manipulate. In the era of consumption, mass culture achieves the goal of full coverage of the population and participation by all people by means of media communication, such as the use of radio, television and network media technologies. At a certain level, the production of public art can't be separated from mass culture. Public art is not restricted by places, it is interactive and communicative. It realizes works through close contact with the audience, and fully realizes zero-distance interaction with the public. Democracy and secularity have become the direct advantage of public art's approaching the masses.
1) Shared symbolic value: The cultural characteristics of the masses in the consumption era are led by consumer culture. In order to meet the higher level of spiritual needs, the practical performance of public art takes the second place, replaced by the symbolic value created by public art. Most of the contemporary works of public art are placed in every corner of the city and integrated into a part of the city, representing the modern ideas and spirit that a city wants to spread, and condensing the cultural essence of the city. As a public artwork representing the image of a city, it carries the cultural deposits and local conditions and customs of a city. As a city "business card", public art also has the same symbolic value.

Taking Xiamen as an example, the "Goddess of Egret" statue has a typical symbolic value as a business card of Xiamen ("Fig. 4").

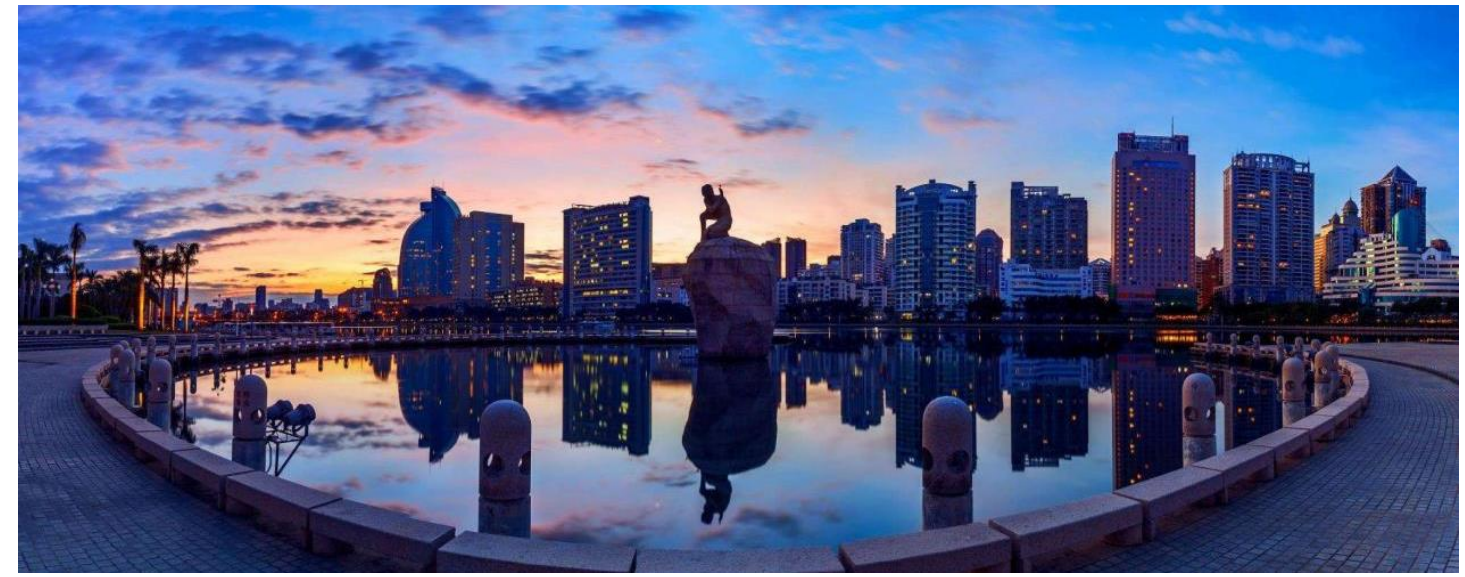

Fig. 4. Xiamen "Goddess of Egret" statue.

2) The interactive influence between public art and the public: Public art has a wider and free space for the public to watch, and there are two-way or even multidirectional communication and exchanges. In the process of communication and interaction with the viewer, it can be divided into two forms: behavioral interaction and thought interaction. The behavioral interaction is often seen in the interaction between sculptures placed in city squares and pedestrians, such as the heart-shaped artwork in Times Square in New York. In order to welcome the arrival of Valentine's Day, the artist installed a lare-scale installation in the center of the square to achieve intimate interaction with pedestrians through the control of high-tech light and shadow. The thought interaction is usually seen when artists directly ask the public to participate in the creation process of public art works. In the process of participating in the creation of artworks, the public will also incorporate their true thoughts and behaviors into the works, making the works the works of the participants. The completion of the work embodies another substantive communication between the artist and the public. The creativity of the public consciously releases inspiration through the stimulation of artists, and the understanding of art is also deeper, and it is possible to create better works of art.

3) Avoiding "misunderstanding" of mass consumption: As China's urbanization process continues to accelerate, while raising funds to improve streets and basic facilities, local governments advocate public art to enrich people's cultural literacy. While the large-scale cultural consumption trend introduces contemporary public artworks, some drawbacks are gradually revealed. When the "Rubber Duck" became popular all over the world, "Rubber Duck" appeared in many cities in China. Although they were similar in appearance, due to the difference in materials and sizes, the image of "Rubber Duck" in the public mind greatly 
declined. Hofmann's original intention was to make the Rubber Duck full of friendship among peoples of all countries and to pass happiness to every corner of the world. However, due to the emergence of copycat products, the role of public art works can't be brought into play, unable to achieve the purpose of raising the level of public art, and may even lead the public to the wrong aesthetic of public art ("Fig. 5" and "Fig. 6"). In addition, the shadow of public art will inevitably appear in the vanity projects of local governments. Therefore, no matter which city, there are shoddy works of art like Li Sheng bronze figures in Wangfujing, similar sculptures in the center of the flower bed in the park, etc. Even some artworks that are constructed with lots of money are forced to be placed in a certain place, which are incompatible with the context of the entire city.

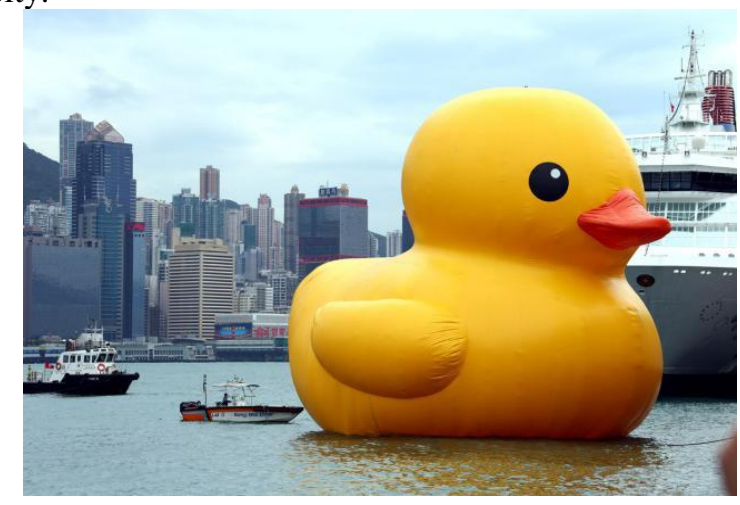

Fig. 5. The authorised edition of Hong Kong Rubber Duck.

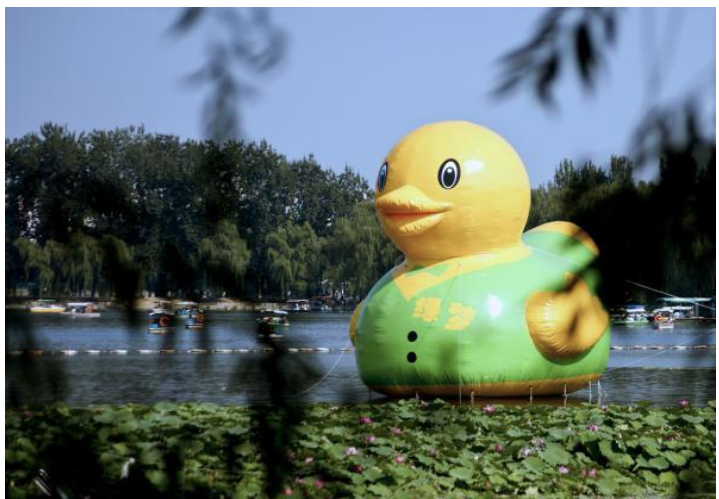

Fig. 6. The copycat Rubber Duck in Beijing Yu Yuan Tan Park.

\section{RESEARCH ON CULTURAL REMODELING OF PUBLIC ART IN THE CONSUMPTION ERA}

\section{A. The cultural remodeling method of public art in the consumption era}

1) Cultural breakthrough: characteristics of regional culture: The integration of public art design and regional culture should emphasize its regional characteristics, highlight the regional cultural characteristics in the design, deepen the cultural connotation of public art design to make creative designs and make public art unique and different from other cities. After public art has regional cultural characteristics, it will also become a new urban regional symbol, spreading the unique culture of the city to the outside world, enhancing the status of the city's image, and promoting the development of the city's economy. The emphasis on regional characteristics in public art landscape design can make urban residents have a strong sense of substitution and make public art closer to the lifestyle and taste of the masses, which can be convenient for ordinary people to appreciate and understand the regional cultural concepts conveyed by public art, strengthen the connection between the city and the residents, enable urban residents to independently maintain and promote urban public art, and at the same time, enable the public art industry to continue to develop.

2) Multiple interactions: art walks into the public: In the era of mass cultural consumption, audiences need to communicate and interact with public art works if they want to understand public art. The interaction between public art works and the public is the process of art information transmission and audience acceptance. Modern public art has changed the traditional one-way and static way of display, facing the public in a more open form and paying more attention to communication and interaction with the public, so that public art can truly enter the public space. Therefore, "interaction" has become an important part of public works of art. In the process of public art creation, it is necessary to consider the interaction with the public. While delivering artistic information to the public, it will bring the public into a state of interactive communication, arouse the audience's ideological and emotional resonance, and receive feedback from the public. The benign interactive communication between public art and the public adds luster to the daily life of the public, and at the same time, it also improves the public's artistic appreciation to a certain extent.

3) Context retention: emotional connection: The diversified forms of public art form an effective connection with the original environmental emotions, expressing the constant rationality and common feelings of human beings. Artists increasingly use new media and mixed media to express their emotional awareness of space in public. In particular, the purpose and functionality of public art coexist in design, and the resulting forms are also diverse. Therefore, what public art creation wants to express is actually the integration 
of the environmental cultural philosophy attitude and spirit and emotion.

\section{B. The cultural remodeling of public art: taking the atrium landscape design plan of Xiamen Academy of Arts and Design as an example}

Xiamen Academy of Arts and Design, as a longestablished art college, its influence in the field of public art plays a huge role in Xiamen's cultural consumption. Its representative works "Goddess of Egret" and "Keep Moving" marathon have become important signs of the city, conveying cultural information, not only recording the history of urban development, integrating public art and urban culture, but also carrying the good memories of the citizens. The following uses the campus atrium landscape design plan as an example to illustrate the cultural reshaping of public art.

1) Acting according to circumstances, and combining local culture to create public art: The campus is a distribution center for students, and the focus of cultural consumption is campus culture. As a branch of mass culture, campus culture has common characteristics with it. Both of them are spontaneously formed under the combined action of the regional natural environment and the humanistic environment, and with the continuous improvement of cultural consumption levels, they slowly settle and develop forward. As the soul of school development, campus culture is an important manifestation of uniting people's hearts, displaying school image, and improving school civilization. Campus culture has a profound influence on students' outlook on life and values, and this influence is often unmatched by any curriculum. On the basis of carrying forward the campus culture inheritance, designing a space that reflects the school spirit, spreads the school's educational philosophy, and refines the school's teaching characteristics is the focus of this design. Therefore, the design is conceived from the starting point of the egret, the spiritual symbol of Xiamen City's bird and the college. It has both local cultural value and artistic value, and based on the history of the development of the college, based on the process of relocating from the old campus on Gulangyu Island to the new campus of Jimei, it uses the concept of "egret's trip" to highlight the connection to the history and context of the college. Through the narrative setting of the egret flying from Gulangyu to Jimei, it enables public art installations to generate a dialogue in time and space between the old and new campus. The origin of the model is abstract editing of the slow motion of egret's flying, and the visual symbols obtained are implanted in the space. And then, it uses light-weight special materials and technology to design, and takes special materials and technology into consideration while focusing on integrating into campus culture, making public art installations more unique and ingeniously integrating the design with the existing landscape. Therefore, it maks public art have the characteristics and ideas of campus culture ("Fig. 7"). 


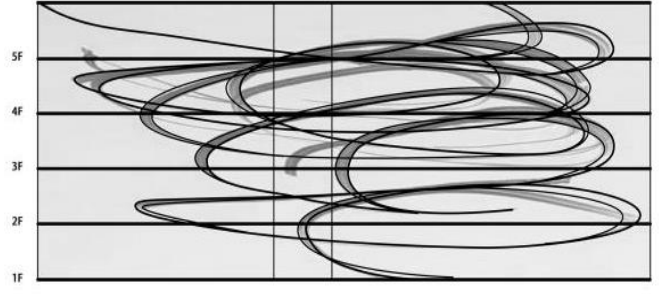

1. Concept implantation

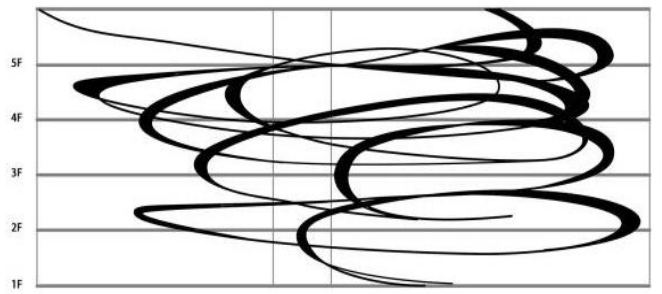

3. Concept extraction

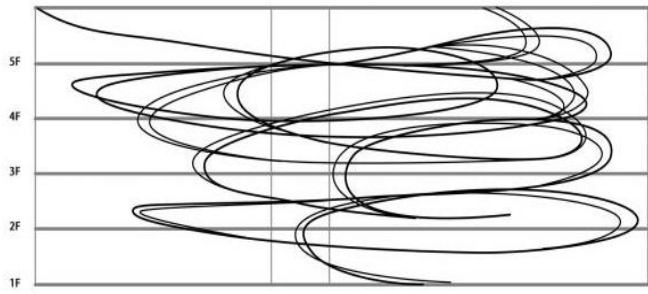

2. Concept evolution

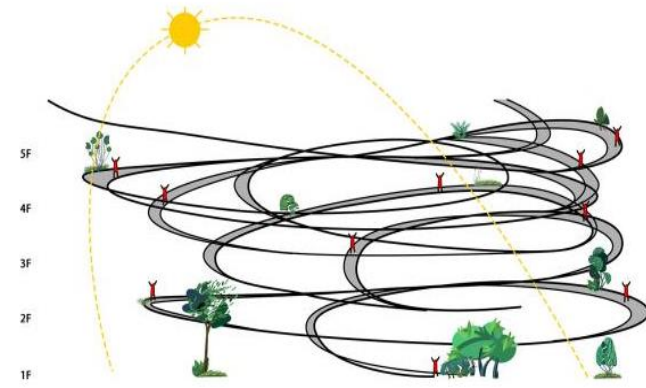

4. Results generated

Fig. 7. The evolution of the concept of "Egret's trip" (drawn by the author).

2) Paying attention to the public's participation and interaction and stimulating the public's creativity: Public art is a dialogue between art and the public, and good interactive communication is the soul of public art creation. The main body of campus public is students. Campus public art has become a new art form that creates free and comfortable activity space for students, meets the aesthetic and emotional needs of most people, and embodies the human-oriented cultural spirit. The human factor is the key that can't be ignored in the creation of public art works, and public participation and co-creation will be the only way for public art works to further demonstrate its charm [3]. How to establish the image of public works of art, make them close to the public, and integrate people and the environment are the primary links of creation. Therefore, more consideration should be given to this factor in the design, and the lifeless and tedious ornament that lacks of spiritual communication should be abandoned, so that the artwork can interact directly with students, and people can create more public art works with high affinity, appeal and interaction. The mimic corridor installation of the egret's flightpath and the simulated wetland landscape ("Fig. 8" and "Fig. 9") enable students to integrate their real thoughts and behaviors into public art installations and become part of public art installations. In this process, art and the public have substantial communication.

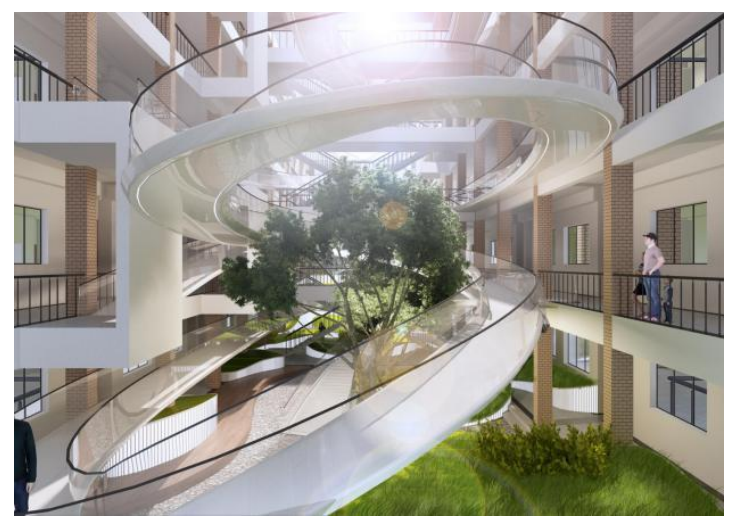

Fig. 8. Indoor public art corridor installation (drawn by the author)

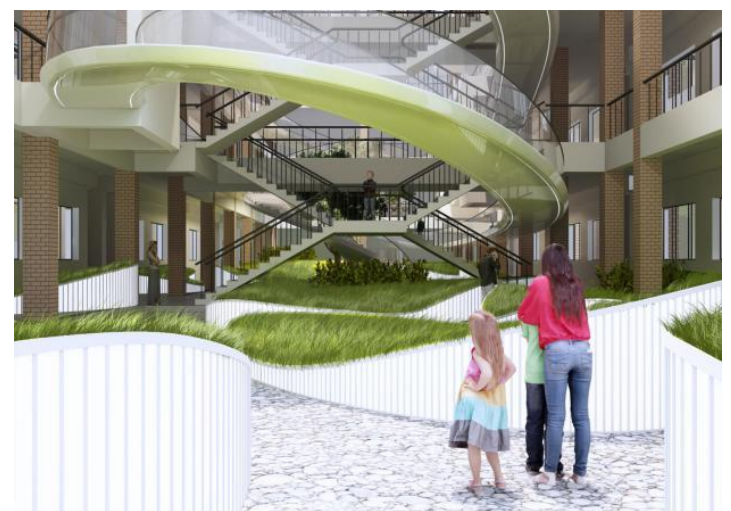

Fig. 9. Greening of the indoor wetland landscape (drawn by the author).

3) Emotional and cultural sublimation: The campus environment is the sum of natural environment and 
humanistic environment, including historical culture, natural environment and humanistic architecture. The formation and development of the Xiamen Academy of Arts and Design not only benefited from its historical environment and other conditions, but also by its own regional restrictions, which led to the birth of the new campus. People living in different campuses naturally have different feelings and dependence on different campuses. Therefore, the design of the atrium of the Xiamen Academy of Arts and Design emphasizes people's sense of belonging and sense of place. The emotional and cultural nature of the public art installation, as well as its interaction with students, are of great significance for its existence. Public art installations full of emotion and cultural connotation can quickly make people associate on the basis of their senses and respond to the environment through certain connotations, so as to meet people's emotional needs and cultural consumption desire.("Fig. 10" and "Fig. 11")

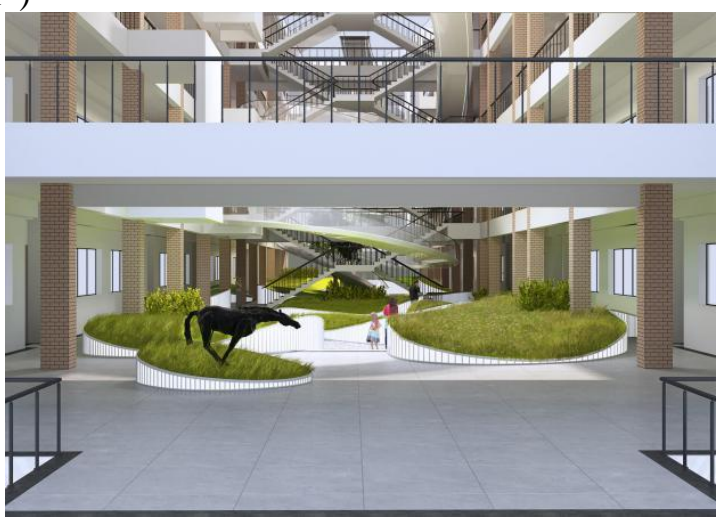

Fig. 10. The first floor of the landscape (drawn by the author).

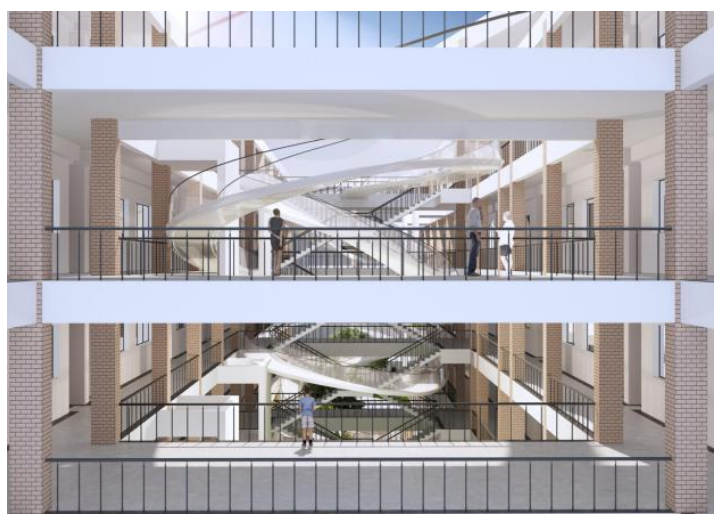

Fig. 11. The fourth floor of the landscape (drawn by the author).

\section{CONCLUSION}

The development of public art can not only satisfy the public's cultural consumption needs, but also play a positive role in building a harmonious society. Facing the coming of the consumption era, the cultural consumption of the masses has gradually extended from the marginal of social thought to every corner, which is closely related to people's lives. Public art in pure form can no longer satisfy the public's consumer aesthetics. In the consumption era with mass culture as the background, the development of public art needs to integrate the consumer culture of the masses. While better inheriting and carrying forward the original culture, it also strengthens the consumer culture atmosphere of art. Public art relies on the development of mass culture to achieve zero-distance contact and communication with the public, which has become an indispensable and important project in urban construction. It is closely related to people's lives, and can contribute to the beautification and quality improvement of the city, and can even assume the mission of carrying urban culture. While meeting people's spiritual aesthetic requirements, it has also become a mainstream cultural form that stands erect in public space.

\section{References}

[1] Li Jun. On the rational structure and thinking of public art value orientation [J]. Arts Circle, 2013(6):84-85. (in Chinese)

[2] Yang Kui. The symbolic characteristics of consumerism culture and mass communication [J]. Journal of Lanzhou University (Social Science Edition), 2003, 31(1):63-67. (in Chinese)

[3] Ma Lichao. Public Art and Public Participation [J]. Drama House, 2013(7):256-256. (in Chinese)

[4] Zhou Chenglu, Jing Yi. Consumerism, Mass Culture and Public Art [J]. Journal of Shanghai University (Social Science Edition), 2008(05):127-133. (in Chinese)

[5] Sun Feiyu. Discussion on the existing problems and development prospects of China's public art design [J]. Trade Union Forum: Journal of Shandong Trade Union Administrative Cadre Institute, 2012. (in Chinese)

[6] Li Lei. The Era of Everyday Aesthetics [M]. Social Sciences Academic Press, 2014. (in Chinese) 